\title{
ERRATUM
}

\section{Estimating effects of ambient PM2.5 exposure on health using PM2.5 component measurements and regression calibration}

MATTHEW STRAND, SVERRE VEDAL, CHARLES RODES, STEVEN J. DUTTON, ERWIN W. GELFAND AND NATHAN RABINOVITCH

Journal of Exposure Science and Environmental Epidemiology (2007) 17, 122. doi:10.1038/sj.jes.7500541

Correction to: Journal of Exposure Science and Environmental Epidemiology (2006) 16: 30-38; advance online publication, July 6, 2005; doi:10.1038/sj.jea.7500434

In terms of equations (5) and (6) as given in the article, the equation at the beginning of the Regression Calibration subsection within Methods (end of page 32) should be

$$
\begin{aligned}
Y_{\text {it }}= & \beta_{0}+\beta_{1} X_{i t}^{A}+\left\{\alpha_{1} W_{i t}^{1}+\ldots+\alpha_{k} W_{i t}^{k}\right\}+\gamma_{i}+\varepsilon_{i t} \\
= & {\left[\beta_{0}+\beta_{1} \theta_{0}\right]+\gamma_{i}+\left[\beta_{1} \theta_{1}\right] X_{t}+\left[\beta_{1} \phi_{i}\right] X_{t} } \\
& +\left\{\alpha_{1} W_{i t}^{1}+\ldots+\alpha_{k} W_{i t}^{k}\right\}+\left[\beta_{1} \omega_{i t}+\varepsilon_{i t}\right]
\end{aligned}
$$

The subject-specific slope of $X_{\mathrm{t}}$ is $\left[\beta_{1}\left(\theta_{1}+\phi_{i}\right)\right]$. However, the fixed-effect (or average) slope of $X_{\mathrm{t}}$ is still $\beta_{1} \theta_{1}$, which is the quantity of interest as described in the article.

The authors would like to apologise for this mistake. 